\title{
Functional characterization of orbicularis oculi and extraocular muscles
}

\author{
Marijana Sekulic-Jablanovic, ${ }^{1,2}$ Nina D. Ullrich, ${ }^{3}$ David Goldblum, ${ }^{4}$ Anja Palmowski-Wolfe, ${ }^{4}$ \\ Francesco Zorzato, ${ }^{1,2,5}$ and Susan Treves ${ }^{1,2,5}$ \\ ${ }^{1}$ Department of Anesthesia and 2Department of Biomedicine, Basel University Hospital, 4031 Basel, Switzerland \\ ${ }^{3}$ Institute of Physiology and Pathophysiology, Department of Cardiovascular Physiology, University of Heidelberg, \\ 69120 Heidelberg, Germany \\ ${ }^{4}$ Eye Clinic, Basel University and Basel University Hospital, 4031 Basel, Switzerland \\ ${ }^{5}$ Department of Life Sciences and Biotechnology, General Pathology Section, University of Ferrara, 44100 Ferrara, Italy
}

\begin{abstract}
The orbicularis oculi are the sphincter muscles of the eyelids and are involved in modulating facial expression. They differ from both limb and extraocular muscles (EOMs) in their histology and biochemistry. Weakness of the orbicularis oculi muscles is a feature of neuromuscular disorders affecting the neuromuscular junction, and weakness of facial muscles and ptosis have also been described in patients with mutations in the ryanodine receptor gene. Here, we investigate human orbicularis oculi muscles and find that they are functionally more similar to quadriceps than to EOMs in terms of excitation-contraction coupling components. In particular, they do not express the cardiac isoform of the dihydropyridine receptor, which we find to be highly expressed in EOMs where it is likely responsible for the large depolarization-induced calcium influx. We further show that human orbicularis oculi and EOMs express high levels of utrophin and low levels of dystrophin, whereas quadriceps express dystrophin and low levels of utrophin. The results of this study highlight the notion that myotubes obtained by explanting satellite cells from different muscles are not functionally identical and retain the physiological characteristics of their muscle of origin. Furthermore, our results indicate that sparing of facial and EOMs in patients with Duchenne muscular dystrophy is the result of the higher levels of utrophin expression.
\end{abstract}

\section{INTRODUCTION}

Excitation-contraction coupling (ECG) is the process whereby an electrical signal, depolarization of the plasma membrane, is converted into a chemical signal, $\mathrm{Ca}^{2+}$ release from the SR, leading to muscle contraction (Caputo, 2011). ECC relies on the function of two main $\mathrm{Ca}^{2+}$ channels, the voltage-sensing dihydropyridine receptor (DHPR), an L-type $\mathrm{Ca}^{2+}$ channel present on the transverse tubules, and the ryanodine receptor (RyR) $\mathrm{Ca}^{2+}$ channel, present on the SR terminal cisternae. In mammalian skeletal muscle, ECC is mechanically coupled, that is membrane depolarization causes the $\alpha 1$ subunit $\left(\mathrm{Ca}_{\mathrm{v}} 1.1\right)$ of the DHPR to undergo a conformational change, causing it to come in direct contact with the RyR1 and leading to release of $\mathrm{Ca}^{2+}$ from the SR (Ríos and Pizarro, 1991). In mammalian cardiac muscles, in contrast, ECC does not rely on mechanical coupling, but rather influx of $\mathrm{Ca}^{2+}$ through the cardiac $\alpha 1$ subunit of the DHPR $\left(\mathrm{Ca}_{\mathrm{v}} 1.2\right)$ activates the cardiac RyR2, leading to release of $\mathrm{Ca}^{2+}$ from the SR (Bers, 2002). Thus, the functional requirements of heart and skeletal muscle are assured by the exquisite specificity of protein isoform expression. This general configuration of skeletal and cardiac ECC protein expression was thought to underlie the function of most striated mus-

\footnotetext{
Correspondence to Susan Treves: susan.treves@unibas.ch

Abbreviations used in this paper: 4-cmc, 4-chloro-m-cresol; DHPR, dihydropyridine receptor; ECC, excitation-contraction coupling; EOM, extraocular muscle; GPCR, quantitative real-time PCR; RyR, ryanodine receptor; SRL, sarcalumenin; TIRF, total internal reflection fluorescence.
}

cles; however, in a recent study on the protein composition of human extraocular muscles (EOMs), we found that hybrid skeletal/cardiac muscle configurations of the ECC machinery can exist. Indeed EOMs express both the skeletal and cardiac isoforms of the $\alpha 1$ subunit of the DHPR, rely on influx of $\mathrm{Ca}^{2+}$ from the extracellular environment, and express not only RyR1 but also RyR3 (Sekulic-Jablanovic et al., 2015).

EOMs, the fastest muscles in the body, derive from somitomeres (preotic mesodermal segments; Wright et al., 2006). There are six EOMs distributed in three antagonistic pairs of muscles that finely control eye movements (Spencer and Porter, 1988); they are innervated by three cranial nerves (III, IV, and VI; Sadeh and Stern, 1984). EOMs are highly specialized and can be either singly innervated or multiply innervated. These characteristics together with the unique expression of myosin heavy chain-EO (MyHC13; Schiaffino and Reggiani, 2011) set them apart from all other skeletal muscles, as a distinctive group of highly specialized muscles (Spencer and Porter, 1988). In contrast, the orbicularis oculi muscles comprise the sphincter muscles of the eyelids; they are classified as facial muscles and functionally antagonize the levator palpebrae superioris muscles,

(c) 2016 Sekulic-Jablanovic et al. This article is distributed under the terms of an AttributionNoncommercial-Share Alike-No Mirror Sites license for the first six months after the publication date (see http://www.rupress.org/terms). After six months it is available under a publication date (see http://www.rupress.org/terms). After six months it is available under a
Creative Commons License (Attribution-Noncommercial-Share Alike 3.0 Unported license, as described at http://creativecommons.org/licenses/by-nc-sa/3.0/). 
which are accessory EOMs (Porter et al., 1998). The orbicularis oculi muscles can be subdivided into orbital, palpebral, and lacrimal portions. The orbital portion firmly closes the eyelids and is controlled by voluntary action; the palpebral portion closes the eyelids gently in involuntary or reflex blinking; the palpebral portion can be further divided into pretarsal, preseptal portion, and ciliary. The lacrimal portion compresses the lacrimal sac, which receives tears from the lacrimal ducts and conveys them into the nasolacrimal duct (Gray and Lewis, 1918). The orbicularis oculi muscles derive from the mesenchyme in the second pharyngeal arch (Moore et al., 2015) and are innervated by the VII cranial nerve (Ouattara et al., 2004).

Weakness of the orbicularis oculi muscles is often apparent in neuromuscular disorders affecting the neuromuscular junction (Miller et al., 2008). Similar to EOMs, they are also one of the first targets of mitochondrial myopathies and myasthenia gravis, resulting in weakness of eyelid closure and ptosis (Miller et al., 2008). Facial weakness and ptosis have also been described in patients with recessive $R Y R 1$ mutations (the gene encoding the RyR1; Taylor et al., 2012), affected by multiminicore disease, congenital fiber type disproportion, and centronuclear disease (Jungbluth et al., 2005; Treves et al., 2008; Clarke et al., 2010; Wilmshurst et al., 2010). In contrast, EOMs are spared in aging, Duchenne muscular dystrophy, and congenital muscular dystrophy when all other skeletal muscles are affected (Kaminski et al., 1992; Khurana et al., 1995; Kallestad et al., 2011). Weakness of the facial musculature caused by any disease is almost certainly accompanied by weakness of the orbicularis oculi muscles as well (Miller et al., 2008). The present investigation was undertaken to identify similarities and differences in ECC and calcium homeostasis in human EOMs, orbicularis oculi, and quadriceps, to identify factors that might contribute to the selective involvement in different neuromuscular disorders. The results of the present investigation show that the ECG machinery and calcium regulation of human orbicularis oculi are more similar to those of quadriceps than of EOMs; in contrast, orbicularis oculi and EOMs are similar in that they both express high levels of utrophin, whereas quadriceps expresses dystrophin. This finding explains the sparing of facial and EOMs in Duchenne patients; because the ECG machinery between orbicularis oculi and quadriceps appears to be similar, our study points to a potential use of autologous facial muscle-derived satellite cells for muscle reimplantation in patients with muscular dystrophy.

\section{MATERIALS AND METHODS}

\section{Human muscle cell cultures}

Primary muscle cell cultures were established as previously described (Censier et al., 1998; Ducreux et al.,
2004) from fragments of muscle biopsies from patients aged between 18 and 65 yr. Quadriceps muscle biopsies were obtained from healthy males or females (six donors) undergoing in vitro diagnostic procedures, orbicularis oculi muscle biopsies were from preseptal muscles of patients $(\approx 75 \%$ females) undergoing eyelid cosmetic procedure or blepharoplasty (five donors), and EOM biopsies were from lateral or medial rector muscles of patients undergoing squint corrective surgery (four donors). Cells were plated on laminin-coated glass coverslips and allowed to grow and differentiate as previously described (Treves et al., 2011; Sekulic-Jablanovic et al., 2015). This research was performed in accordance with the Declaration of Helsinki (2013) of the World Medical Association and was approved by the Ethikkommission beider Basel (permit $\mathrm{N}^{\circ}$ EK64/12); all subjects gave written informed consent to carry out this work.

\section{Calcium measurements and spark analysis}

Fura-2/AM (EMD Millipore) or fluo-4/AM (Thermo Fisher Scientific) at a final concentration of $5 \mu \mathrm{M}$ was used to load myotubes for $30 \mathrm{~min}$ at $37^{\circ} \mathrm{C}$, after which the coverslips were mounted onto a $37^{\circ} \mathrm{C}$ thermostatically controlled chamber that was continuously perfused with Krebs-Ringer medium; individual cells were stimulated by means of a 12- or 8-way 100-mm-diameter quartz micromanifold computer-controlled microperfuser (ALA Scientific Instruments), as described previously (Ducreux et al., 2004). The ratiometric $\mathrm{Ca}^{2+}$ indicator fura-2 was used for monitoring the global changes in the cytoplasmic $\mathrm{Ca}^{2+}$ concentration as previously described (Censier et al., 1998; Ducreux et al., 2004). Ratiometric images ( $340 / 380 \mathrm{~nm})$ were acquired every $1 \mathrm{~s}$, and the camera was set at a fixed exposure time of $100 \mathrm{~ms}$. Fura-2 fluorescence ratio signals were converted into $\left[\mathrm{Ca}^{2+}\right]$ using the curve generated using the fura-2 $\mathrm{Ca}^{2+}$ imaging calibration kit from Molecular Probes as previously described (Vukcevic et al., 2013). The total amount of rapidly releasable $\mathrm{Ca}^{2+}$ in the stores was determined as previously described (Rokach et al., 2013) by calculating the area under the curve of the transient induced by the application of $1 \mu \mathrm{M}$ ionomycin, plus $1 \mu \mathrm{M}$ thapsigargin in Krebs-Ringer containing $0.5 \mathrm{mM}$ EGTA.

The dynamics of depolarization-induced $\mathrm{Ca}^{2+}$ influx were investigated by total internal reflection fluorescence (TIRF) microscopy using the single wavelength $\mathrm{Ca}^{2+}$ indicator fluo-4 as detailed previously (Treves et al., 2011; Ullrich et al., 2011). Myotubes were pretreated with $50 \mu \mathrm{M}$ ryanodine (EMD Millipore) to block $\mathrm{Ca}^{2+}$ release through the RyR1 receptor (Treves et al., 2011), and depolarization-induced $\mathrm{Ca}^{2+}$ entry was stimulated by the application of $60 \mathrm{mM} \mathrm{KCl}$. Online fluorescence images were acquired every $100 \mathrm{~ms}$ using an inverted Nikon TE2000 TIRF microscope equipped with an oil immersion CFI Plan Apochromat 60× TIRF objective 
(1.49 NA) and an electron multiplier Hamamatsu CCD camera (C9100-13). The MetaMorph imaging software from Molecular Devices was used for analysis of the fluorescence changes.

\section{Quantitative real-time PCR (qPCR)}

Total RNA was extracted from muscle biopsies using TRIzol (Invitrogen) according to the manufacturer's instructions. RNA was first treated with deoxyribonuclease I (Invitrogen), and then 1,000 ng was reverse transcribed using the high-capacity cDNA reverse transcription kit (Applied Biosystems). cDNA was amplified by qPCR using SYBR Green technology (Fast SYBR Green Master Mix; Applied Biosystems) as previously described (Rokach et al., 2013). The sequences of the primers used for gene amplification and quantification are given in Table S1. qPCR was performed on a 7500 Fast Real-Time PCR machine (Applied Biosystems) using the 7500 software v2.3 as previously described (Sekulic-Jablanovic et al., 2015). Gene expression was normalized to expression of ACTN2, which is present in all muscle fiber types. Results are expressed as fold change compared with expression of the gene in quadriceps muscles.

\section{Immunofluorescence}

Differentiated human myotubes grown on a glass coverslip coated with laminin were fixed with $4 \%$ paraformaldehyde (made in PBS), permeabilized with $1 \%$ Triton in PBS for $20 \mathrm{~min}$, and processed as previously described (Treves et al., 2011). The following antibodies were used: mouse anti-RyR1 (MA3-925; Thermo Fisher Scientific), goat anti-Ca 1.1 (sc-8160; Santa Cruz Biotechnology, Inc.), rabbit anti-Ca 1 1.2 (sc-25686; Santa Cruz Biotechnology, Inc.), mouse anti-dystrophin (ab7164; Abcam), rabbit anti-utrophin (sc-15377; Santa Cruz Biotechnology, Inc.), Alexa Fluor 488-conjugated chicken anti-rabbit, Alexa Fluor 555-conjugated donkey anti-goat IgG (Thermo Fisher Scientific), and Alexa Fluor 647-conjugated goat anti-mouse IgG (Thermo Fisher Scientific). Cells were stained with $4^{\prime}$, 6-diamidino-2-phenylindole (DAPI; Thermo Fisher Scientific) to visualize nuclei and observed using an A1R confocal microscope (Nikon) with a CFI Apo TIRF $100 \times(1.49 \mathrm{NA})$ objective.

\section{Electrophoresis and immunoblotting}

The total SR fraction was isolated from flash-frozen muscle samples (human orbicularis oculi, EOM, quadriceps muscles, and mouse heart) as previously described (Anderson et al., 2003) and stored in liquid nitrogen. The protein concentration was determined using the Protein Assay kit II (Bio-Rad Laboratories) and BSA as a standard. SDS-PAGE, protein transfer on to nitrocellulose membranes, and immunostaining were performed as previously described (Anderson et al., 2003). The following primary antibodies were used: mouse anti-RyR1 (MA3-925; Thermo Fisher Scientific), goat anti-Ca $\mathrm{v}_{\mathrm{v}} 1.1$ (sc-8160; Santa Cruz Biotechnology, Inc.), rabbit anti-Ca 1.2 (sc-25686; Santa Cruz Biotechnology, Inc.), rabbit anti-calsequestrin 1 (C-0743; Sigma-Aldrich), anti-calsequestrin 2 (3516; Abcam), goat anti-SERCA1 (sc-8093; Santa Cruz Biotechnology, Inc.), mouse anti-sarcalumenin (SRL; MA3-932; Thermo Fisher Scientific), anti-dystrophin (ab-7164; Abcam), anti-utrophin (sc-15377; Santa Cruz Biotechnology, Inc.), and mouse anti-myosin heavy chain (05-716; EMD Millipore). Secondary peroxidase conjugates were protein G-peroxidase (P8170; Sigma-Aldrich) and peroxidase-conjugated goat anti-mouse IgG (A2304; Sigma-Aldrich). The immunopositive bands were visualized by chemiluminescence using the Super Signal West Dura kit (Thermo Fisher Scientific) or the Chemiluminescence kit (Roche).

For myosin heavy chain, gels were performed as described by Talmadge and Roy (1993) except that $30 \mu \mathrm{g}$ total protein extracts were separated and the final acrylamide concentration was $6.5 \%$. Gels were stained with Coomassie brilliant blue.

\section{Statistical analysis}

Statistical analysis was performed using the Student's $t$ test for two populations. Values were considered significant when $\mathrm{P}<0.05$. When more than two groups were compared, analysis was performed by the ANO VA test followed by the Bonferroni post hoc test, using Prism 4.0 software (GraphPad Software). OriginPro 8.6 software (OriginLab) was used for generating doseresponse curves.

\section{Methods used in supplemental material}

Voltage dependence of $\mathrm{Ca}^{2+}$ release. Orbicularis oculiderived myotubes were patch clamped in the whole cell configuration and stimulated to different depolarizing potentials to elicit $\mathrm{SR} \mathrm{Ca}^{2+}$ release as previously reported using a EPC10 amplifier (HEKA) controlled by the data acquisition software PatchMaster (Rokach et al., 2013). External recording solution contained $(\mathrm{mM}) 130$ TEA$\mathrm{CH}_{3} \mathrm{SO}_{3}, 2 \mathrm{CaCl}_{2}, 1 \mathrm{MgCl}_{2}, 10$ HEPES, $1 \mu \mathrm{M}$ tetrodotoxin, and 14 -aminopyridine, $\mathrm{pH} 7.4(\mathrm{CsOH})$. Internal pipette solution contained (mM) $100 \mathrm{Cs}-\mathrm{CH}_{3} \mathrm{SO}_{3}, 10$ HEPES, $6 \mathrm{MgCl}_{2}$, $11.5 \mathrm{CaCl}_{2}, 4 \mathrm{Na}_{2} \mathrm{ATP}, 10$ EGTA, and $0.1 \mathrm{~K}_{5}$-fluo-3, pH $7.2(\mathrm{CsOH})$. Solution exchange was controlled by an electrically controlled rapid switch microperfuser (VC8; Ala Scientific Instruments). Starting from a holding potential of $-80 \mathrm{mV}$, the voltage clamp protocol consisted of consecutive depolarizing 500-ms step pulses to increasing potentials ranging from -50 to $50 \mathrm{mV}$ with an increment of $10 \mathrm{mV}$. In parallel, changes in cytosolic $\mathrm{Ca}^{2+}$ in clamped cells were recorded by imaging of the fluorescent $\mathrm{Ca}^{2+}$-sensitive indicator fluo-3 using a confocal microscope in the line scan mode 
(IX81, FluoView FV1000, 60× water objective, NA 1.2; Olympus). Excitation of fluo-3 was achieved at $473 \mathrm{~nm}$, and emission was collected between 510 and $560 \mathrm{~nm}$. Line scans were acquired at a rate of $5.6 \mathrm{~ms}$ per line. To acquire multiple line scans from each cell, the duration of the single line scan image was limited to 1,000 lines to avoid photobleaching and cell damage. Experiments were performed at constant room temperature. Images were analyzed using Image (National Institutes of Health) and further processed together with current analysis in OriginPro 2015 software.

Spark measurements. Sparks were measured in fluo-4loaded myotubes using an A1R laser-scanning confocal microscope (Nikon) with a $60 \times$ oil immersion Plan Apochromat VC objective (Nikon; NA 1.4) as previously described (Lopez et al., 2015). 5-s duration line scan images $(\mathrm{x}, \mathrm{t})$ were acquired in resonant mode at 7,680 lps with 512 pixels $(0.05 \mu \mathrm{m} / \mathrm{pixel})$ in the $\mathrm{x}$ and 39,936 pixels $(0.126 \mathrm{~ms} / \mathrm{pixel})$ in the $\mathrm{t}$ direction using a pinhole size of $72.27 \mu \mathrm{m}$. Four to five images were taken at different positions across each cell. The $\mathrm{Ca}^{2+}$ indicator was excited with a laser at $487 \mathrm{~nm}$, and the fluorescence emitted at $525 \pm 25 \mathrm{~nm}$ was recorded. To minimize photo damage, the laser intensity was set at $3 \sim 4 \%$ of the maximal power. Cells were perfused with Krebs-Ringer containing $2 \mathrm{mM} \mathrm{Ca}{ }^{2+}$.

\section{Online supplemental material}

Fig. S1 shows the voltage dependence of $\mathrm{Ca}^{2+}$ release in orbicularis oculi-derived myotubes. Fig. S2 shows that human myotubes do not show spontaneous $\mathrm{Ca}^{2+}$ release events (SPARKS). Table S1 lists the sequence of primers used for qPCR. Online supplemental material is available at http://www.jgp.org/cgi/content/full/ jgp.201511542/DC1.

\section{RESULTS}

Gene and protein expression levels in human orbicularis oculi, EOM, and quadriceps muscles

The expression levels of the major gene products involved in skeletal ECC are shown in Fig. $1 \mathrm{~A}$; the values obtained from orbicularis oculi were compared with those obtained from quadriceps of healthy donors. The latter muscles were used as reference, and the expression level of different genes therein was set to 1 . The results show the mean $( \pm$ SEM) expression level of genes from five pooled biopsy samples normalized to ACTN2. The expression of RYR1 and SERCA1 transcripts was slightly elevated (approximately twofold; $\mathrm{P}<0.05$, Student's $t$ test), as was that of CASQ1, RYR3, and CAC NA1C (4-, 5-, and 10-fold, respectively; $\mathrm{P}<0.0001$, Student's $t$ test), whereas CACNA1S expression was similar in orbicularis oculi and quadriceps muscles. Interestingly, the expression levels of UTRN and DMD showed an $~ 13$ - and 16-fold increase, respectively, compared with quadriceps muscles $(\mathrm{P}<0.0001$, Student's $t$ test $)$. Although it was reported that the MYH13 isoform is exclusively expressed in EOMs (Wieczorek et al., 1985), we also found that it is expressed in orbicularis oculi (Fig. 1 B). JP45 levels remained unchanged.

Total SR fractions were prepared and probed with antibodies against the major skeletal ECC proteins as well as $\mathrm{Ca}_{\mathrm{v}} 1.2$ and CASQ2; the intensities of the immunoreactive bands were normalized to SRL content and are expressed as percent expression of that of quadriceps muscles. Surprisingly, at the protein level, the content of RyR1, $\mathrm{Ca}_{\mathrm{v}} 1.1$, SERCA1, and CASQ1 were not changed between orbicularis oculi and quadriceps (Fig. $1 \mathrm{C}$ ), whereas CASQ2 was significantly increased. We chose to normalize to SRL content and not to SER CA1 or CASQ1 because by qPCR both SERCA1 and CASQ1 transcripts were significantly increased in orbicularis oculi. $\mathrm{Ca}_{\mathrm{v}} 1.2$, the cardiac isoform of the DHPR, could not be detected in Western blots of orbicularis oculi and quadriceps, but it was clearly present in human EOM and mouse heart, which served as positive control (Fig. 1 D). Utrophin was highly expressed in both EOM and orbicularis oculi but less so in quadriceps (fourfold in orbicularis oculi vs. quadriceps; $\mathrm{P}<$ $0.05)$, whereas the opposite was true for dystrophin (orbicularis oculi expressed $\sim 50 \%$ compared with quadriceps; $\mathrm{P}<0.05$; Fig. $1 \mathrm{E})$.

\section{$\mathrm{Ca}^{2+}$ homeostasis in human myotubes derived from} orbicularis oculi, EOM, and quadriceps

Because in a previous study we showed that primary cultures of myotubes explanted from human EOM biopsies had different $\mathrm{Ca}^{2+}$ handling properties (Sekulic-Jablanovic et al., 2015), in the next series of experiments we compared $\mathrm{Ca}^{2+}$ homeostasis in myotubes derived from the three types of muscles. In this context, it should also be mentioned that human myotubes are different from mouse myotubes or fibers in that they do not contract even after exposure to high concentrations of $\mathrm{KCl}$, 4-chloro-m-cresol $(4-\mathrm{cmc})$ or ionomycin plus thapsigargin. In the first set of experiments, cells were perfused with Krebs-Ringer containing $100 \mu \mathrm{M} \mathrm{La}^{3+}$ to prevent influx of extracellular $\mathrm{Ca}^{2+}$ and to ensure that the measurements represent skeletal ECC. Fig. 2 A shows representative fura- 2 traces of a quadriceps-derived myotube (continuous line), orbicularis oculi-derived myotube (dashed line), and EOM-derived myotube (dotted line) in response to $60 \mathrm{mM} \mathrm{KCl}$. Fig. 2 (B and C) shows the KCl- and 4-cmc-induced $\mathrm{Ca}^{2+}$ release curves, respectively. There were no significant differences between the three types of myotubes as far as peak $\mathrm{Ca}^{2+}$ release elicited by either $\mathrm{KCl}$ or $4-\mathrm{cmc}$ is concerned. Furthermore, the $\mathrm{EC}_{50}$ for $\mathrm{KCl}$ (depolarization)-induced $\mathrm{Ca}^{2+}$ release was similar in the three types of myotubes, whereas the $\mathrm{EC}_{50}$ for 4 -cmc-induced $\mathrm{Ca}^{2+}$ 


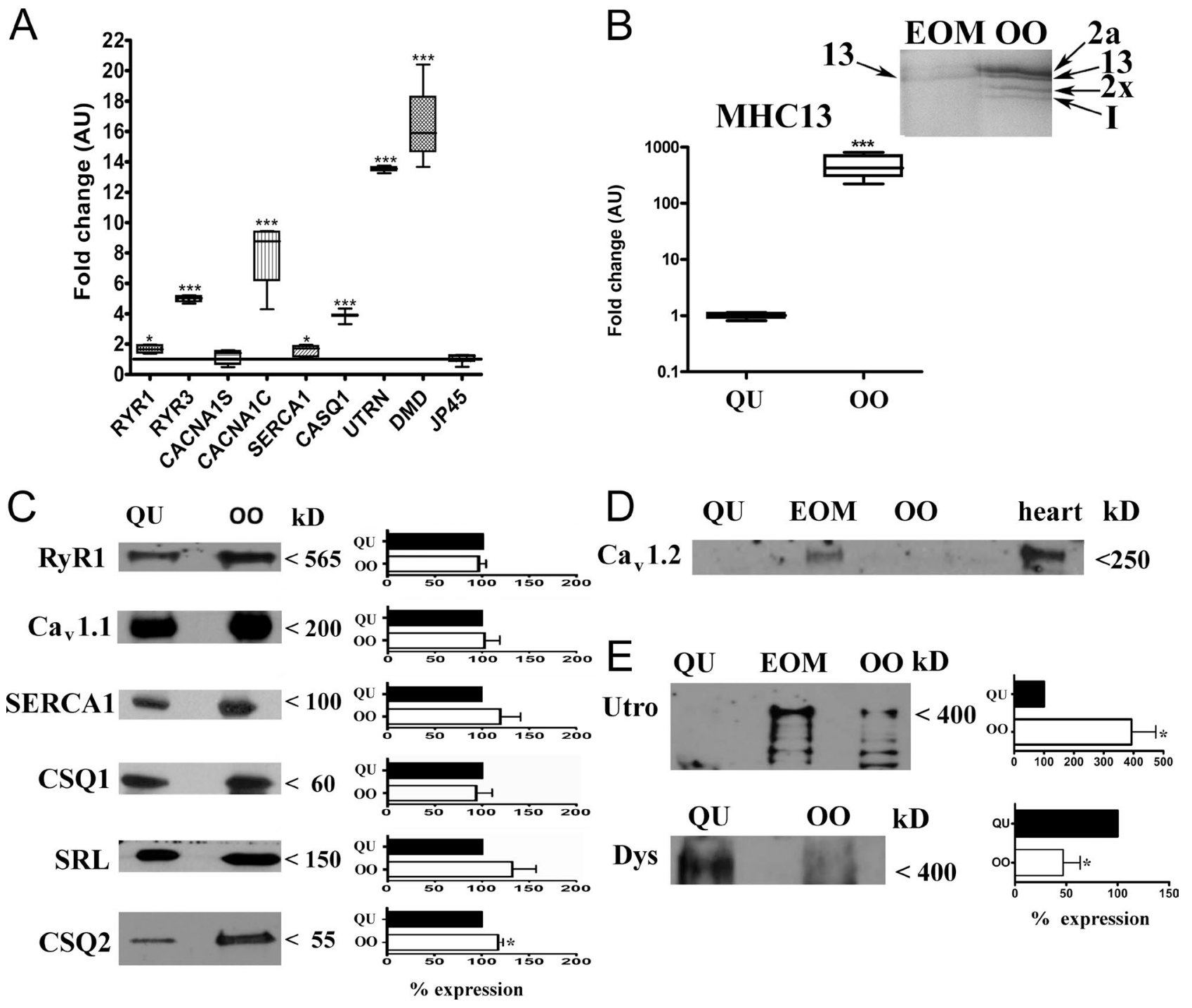

Figure 1. Expression of major ECC transcripts and proteins in human orbicularis oculi muscle biopsies. (A) Gene expression was performed by qPCR as described in Materials and methods. Each reaction was performed in triplicate, in pooled muscle samples from five biopsies from different individuals. Expression levels were normalized to ACTN2 expression. Results are expressed as mean fold change of transcripts in orbicularis oculi compared with quadriceps; the latter was set as 1. Results were analyzed using the Student's $t$ test: ${ }^{*}, \mathrm{P}<0.05 ;{ }^{* * *}, \mathrm{P}<0.0001$. (B) MYH13 gene expression was performed by qPCR as described in Materials and methods. Each reaction was performed in triplicate, in pooled muscle samples from five biopsies from different individuals. Expression levels were normalized to ACTN2 expression. Results are expressed as mean fold change of transcripts in orbicularis oculi (OO) compared with

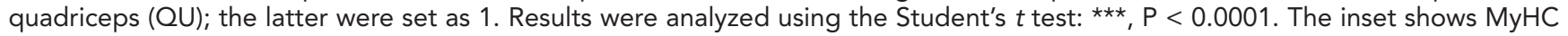
protein expression in EOM and orbicularis oculi muscle homogenates; 10 and $30 \mu \mathrm{g}$ protein were loaded per lane, respectively. Gels and conditions were as described in Materials and methods. (C) Western blot analysis of total SR proteins in human orbicularis oculi and quadriceps muscles. $30 \mu \mathrm{g}$ of protein was loaded per lane and separated on $6 \%$ or $10 \%$ SDS-PAGE. Blots were probed with the indicated antibodies. Bar histograms represent the mean $( \pm S E M)$ band intensity normalized to $S R L$ content. ${ }^{*}, P<0.05$. (D) Western blot of human quadriceps, EOM, orbicularis oculi, and mouse heart (positive control) total SR proteins, probed with Cav 1.2 antibody. $30 \mu \mathrm{g}$ of protein was loaded per lane and separated on 6\% SDS-PAGE. (E) Western blot of total muscle extracts; $30 \mu \mathrm{g}$ of protein was loaded per lane, separated on 6\% SDS-PAGE, and probed with anti-utrophin (top) and anti-dystrophin (bottom) antibodies. Bar histograms represent the mean $\left( \pm\right.$ SEM) band intensity normalized to MyHC content. Student's $t$ test: ${ }^{*}, \mathrm{P}<0.05$.

release was significantly different only between orbicularis oculi- and EOM-derived myotubes (Table 1). We also verified the voltage dependence of $\mathrm{Ca}^{2+}$ release of orbicularis oculi-derived myotubes; the half-maximal release activation $\mathrm{V}_{1 / 2}$ was $-25 \pm 5 \mathrm{mV}$ (Fig. S1), a value similar to that previously reported in quadriceps-de- rived myotubes (Rokach et al., 2013), confirming that the ECC is very similar in both kinds of myotubes. Interestingly, however, there were differences in the mean global resting $\left[\mathrm{Ca}^{2+}\right]_{\mathrm{i}}$ in the three populations of myotubes, though we could not ascertain whether this was caused by large differences within cytoplasmic micro/ 
nanodomains or by a uniform difference resulting from the presence, for example, of different cytoplasmic calcium buffering proteins. The size of the intracellular $\mathrm{Ca}^{2+}$ stores of orbicularis oculi-derived myotubes was similar to those of quadriceps-derived myotubes but significantly lower than those of EOM-derived myotubes (Fig. 2, C and D; P $<0.0001$, Student's $t$ test). We also examined the different types of myotubes for the presence of $\mathrm{Ca}^{2+}$ sparks by high-speed confocal microscopy, but none of the myotubes exhibited sparks (Fig. S2).

We next investigated the process by which membrane depolarization activates $\mathrm{Ca}^{2+}$ influx through the DHPRor depolarization-induced $\mathrm{Ca}^{2+}$ influx (Bannister et al., 2009) by TIRF microscopy as previously described (Treves et al., 2011). Fig. 3 A shows pseudocolored fluo-4 fluorescent changes in a representative myotube pretreated with $50 \mu \mathrm{M}$ ryanodine and stimulated with
Table 1. $\mathrm{EC}_{50}$ for $\mathrm{KCl}$ - and 4-cmc-induced $\mathrm{Ca}^{2+}$ release from myotubes from human quadriceps, orbicularis oculi, and EOMs

\begin{tabular}{lcc}
\hline Tissue of origin & KCl $\mathbf{~ E C}_{\mathbf{5 0}}$ & ${\text { 4-cmc } \mathbf{E C}_{\mathbf{5 0}} \mathbf{a}}^{\mathbf{a}}$ \\
\hline & $m M$ & $\mu M$ \\
Quadriceps & $16.0 \pm 2.0$ & $234.0 \pm 58$ \\
Orbicularis oculi & $19.5 \pm 4.0$ & $206.6 \pm 24^{\mathrm{b}}$ \\
EOM & $10.2 \pm 5.0$ & $332.0 \pm 26$ \\
\hline
\end{tabular}

${ }^{a} \mathrm{ANOVA}$ did not reveal any differences in the $\mathrm{EC}_{50}$ to $\mathrm{KCl}$ between the three types of myotubes. Significant differences were obtained in the $\mathrm{EC}_{50}$ to 4 -cmc, and the Bonferroni post hoc test confirmed the difference to be significant between EOM- and orbicularis oculi-derived myotubes. ${ }^{\mathrm{b}} \mathrm{P}<0.02$.

$60 \mathrm{mM} \mathrm{KCl}$; the pretreatment with high concentrations of ryanodine is necessary to block $\mathrm{Ca}^{2+}$ release through RyR, ensuring that the change in fluo- 4 fluorescence is not caused by $\mathrm{Ca}^{2+}$ release from the $\mathrm{SR}$, but rather from

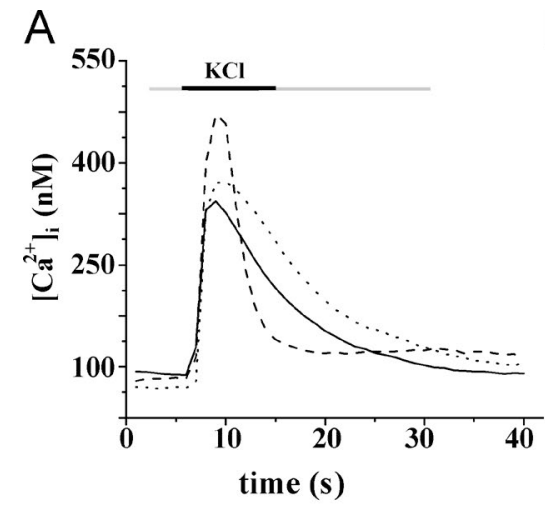

D

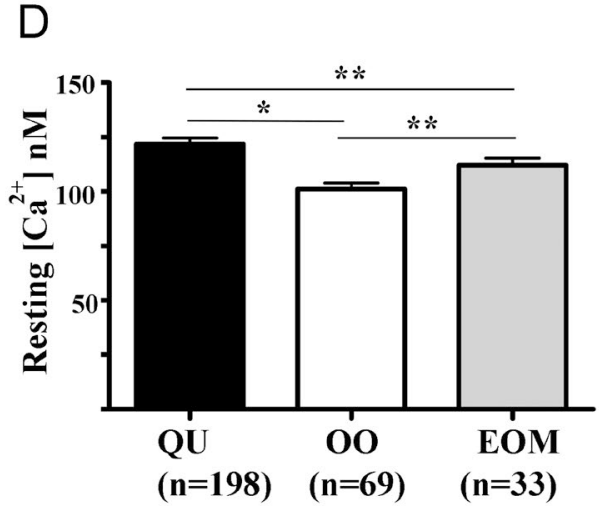

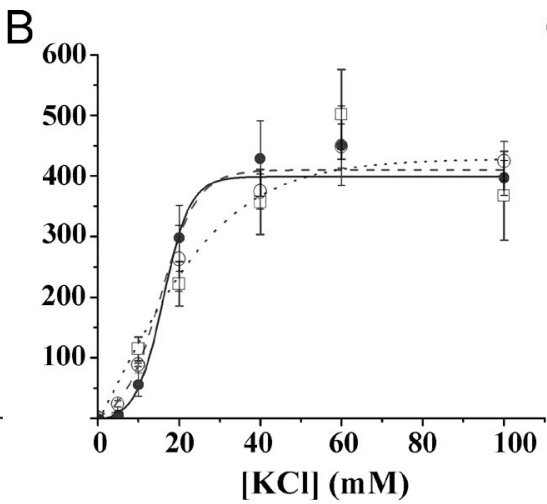
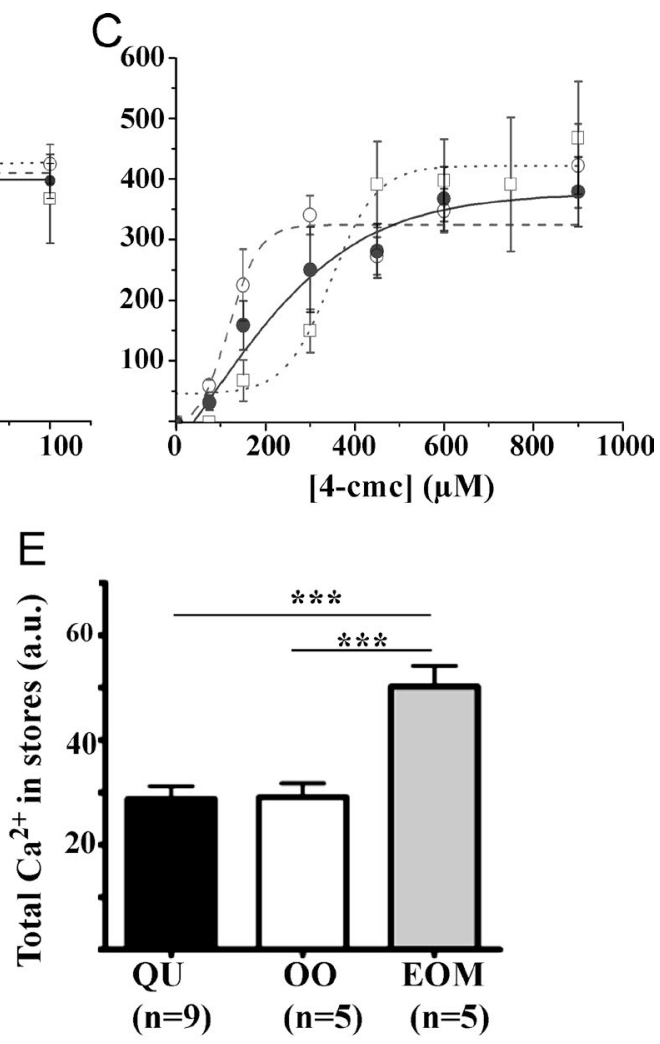

Figure 2. Calcium homeostasis of orbicularis oculi-derived myotubes compared with quadriceps- and EOM-derived myotubes. (A) Representative traces showing changes in $\left[\mathrm{Ca}^{2+}\right]_{i}$ induced by stimulation with $\mathrm{KCl}$. Individual cells were perfused in KrebsRinger containing $100 \mu \mathrm{M} \mathrm{La}{ }^{3+}$ (light gray bar) and then stimulated with $60 \mathrm{mM} \mathrm{KCl}$ for $10 \mathrm{~s}$ (black bar). Ratiometric images (340 $\mathrm{nm} / 380 \mathrm{~nm}$ ) were acquired and converted into $\left[\mathrm{Ca}^{2+}\right]$ as described in Materials and methods. Continuous line, quadriceps-derived myotubes; dashed line, orbicularis oculi-derived myotubes; dotted line, EOM-derived myotubes. (B and $\mathrm{C}$ ) $\mathrm{KCl}$ dose-response curves (B) and 4-cmc dose-response curves (C). Closed circles and continuous lines, quadriceps-derived myotubes; open circles and dashed lines, orbicularis oculi-derived myotubes; open squares and dotted lines, EOM-derived myotubes. Curves were generated using the sigmoidal fit function of the Origin software and show the changes in peak calcium, expressed as $\left[\mathrm{Ca}^{2+}\right]$ in $\mathrm{nM}$. Each point represents the mean ( \pm SEM) of 5-12 different cells. For $\mathrm{KCl}$ - and 4-cmc-induced $\mathrm{Ca}^{2+}$ release, individual cells were perfused with Krebs-Ringer plus $100 \mu \mathrm{M} \mathrm{La}{ }^{3+}$, and the indicated concentration of agonist was applied using a microperfusion system. (D) Mean $\left( \pm\right.$ SEM) resting $\left[\mathrm{Ca}^{2+}\right] .{ }^{*}, \mathrm{P}<0.05 ;{ }^{* *}, \mathrm{P}<0.001$. (E) Total amount of $\mathrm{Ca}^{2+}$ in the SR. Values represent the mean $( \pm \mathrm{SEM})$ calculated area under the curve. Student's $t$ test: ${ }^{\star \star \star}, P<0.0001$. For quadriceps (QU)-derived myotubes, cells from six donors were measured; for orbicularis oculi (OO)-derived myotubes, cells from five donors were measured; and for EOM-derived myotubes, cells from four donors were measured. 


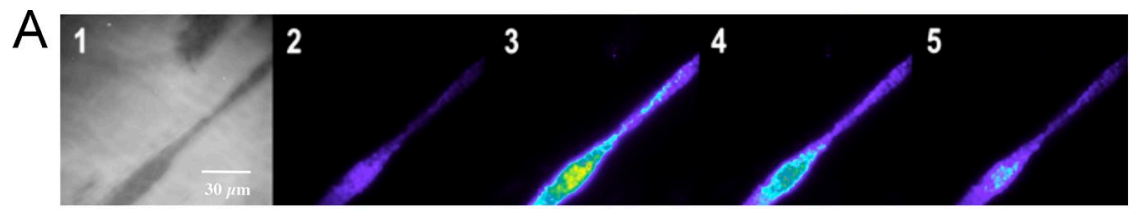

B

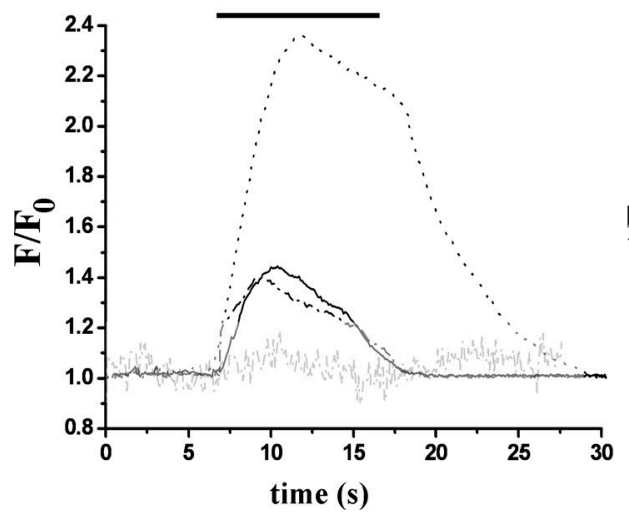

C

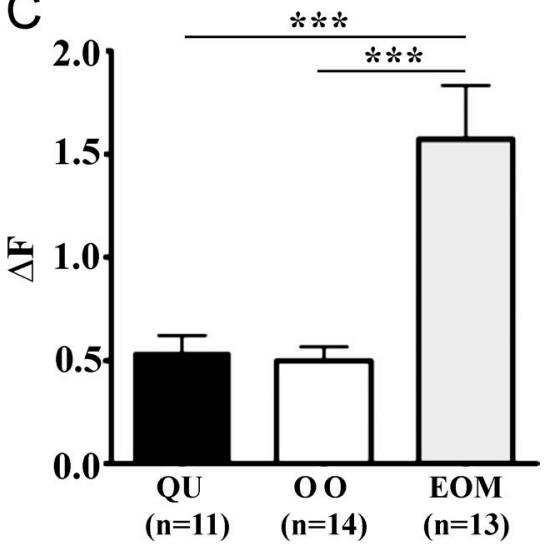

Figure 3. Depolarization-induced $\mathrm{Ca}^{2+}$ influx in orbicularis oculi-, EOM-, and quadriceps-derived myotubes. $\mathrm{Ca}^{2+}$ influx induced by the addition of $60 \mathrm{mM}$ $\mathrm{KCl}$ was monitored using a TIRF microscope as described in Materials and methods and detailed in Treves et al. (2011). (A) Pseudocolored ratiometric images of fluorescence changes (peak fluorescence after addition of $\mathrm{KCl} /$ resting fluorescence) after application of $60 \mathrm{mM}$ $\mathrm{KCl}$ to orbicularis oculi-derived myotubes. 1, EpiSRIC image; 2-5, images at $2,5,11$, and $20 \mathrm{~s}$ after the addition of $\mathrm{KCl}$. The dark gray area within the EpiSRIC image showing the "footprint" of the cell on the glass coverslip was used as a template to draw a mask of the region of interest where calcium changes were measured. Bar, $30 \mu \mathrm{m}$. (B) Representative depolarization-induced $\mathrm{Ca}^{2+}$ influx traces in quadriceps-derived (continuous line), orbicularis oculi-derived (dashed line), and EOM-derived myotubes (dotted line). The black bar indicates the addition of $60 \mathrm{mM} \mathrm{KCl}$. The gray line shows the lack of response of an EOM-derived myotube when the experiment was performed in a solution containing $100 \mu \mathrm{M} \mathrm{La}{ }^{3+}$. (C) Mean ( \pm SEM) peak fluorescence increase induced by $60 \mathrm{mM} \mathrm{KCl}$ in quadriceps (QU)-derived myotubes (black bar), orbicularis oculi (OO)-derived myotubes (white bar), and EOM-derived myotubes (gray bar). Experiments were performed on cells obtained from at least four different biopsies, and results were averaged. Statistical analysis was performed using the ANOVA test: $* \star \star, P<0.0001$.

$\mathrm{Ca}^{2+}$ influx. Fig. 3 B shows a representative $\mathrm{Ca}^{2+}$ influx trace initiated by the application of $60 \mathrm{mM} \mathrm{KCl}$ in orbicularis oculi-derived myotubes (solid trace) quadricepsderived myotubes (dashed trace), and EOM-derived myotubes (dotted trace). A control experiment performed on EOM-derived myotubes showing that no $\mathrm{Ca}^{2+}$ influx occurs when the same experiment is performed in the presence of $100 \mu \mathrm{M} \mathrm{La}^{3+}$ is also shown (dash-dotted trace). Fig. $3 \mathrm{C}$ summarizes the results confirming that depolarization-induced $\mathrm{Ca}^{2+}$ influx in orbicularis oculi myotubes is not significantly different from quadriceps myotubes, but almost threefold lower compared with EOM-derived myotubes.

The difference in $\mathrm{Ca}^{2+}$ influx between EOM and orbicularis oculi muscles most likely reflects the differential expression of $\mathrm{Ca}_{\mathrm{v}}$ isoforms in these groups of muscles. This is confirmed by results depicted in Fig. 4 showing the subcellular distribution of $\mathrm{Ca}_{\mathrm{v}} 1.1, \mathrm{Ca}_{\mathrm{v}} 1.2$, and RyR1 in orbicularis oculi-and EOM-derived myotubes; the distribution of $\mathrm{Ca}_{v} 1.1$ (Fig. 4 A, green) and RyR1 (Fig. 4 B, red) was punctate and unstructured within an intracellular membrane compartment. Although they lack a mature organization, $\mathrm{RyR} 1$ and $\mathrm{Ca}_{\mathrm{v}} 1.1$ codistributed within the myotube (Fig. 4 C). However, $\mathrm{Ca}_{\mathrm{v}} 1.2$ could not be detected in orbicularis oculi-derived myotubes (Fig. 4 D). A similar subcellular punctate distribution of $\mathrm{Ca}_{\mathrm{v}} 1.1$ (Fig. $4 \mathrm{E}$ ) and RyR1 (Fig. $4 \mathrm{~F}$ ) was found in EOM-derived myotubes; however, in the latter cells,
$\mathrm{Ca}_{\mathrm{v}} 1.2$ was exclusively targeted to the plasma membrane (Fig. $4 \mathrm{H}$ ).

Dystrophin and utrophin expression and subcellular distribution in myotubes derived from orbicularis oculi, EOM, and quadriceps

Because qPCR and Western blot analysis revealed that orbicularis oculi and EOM but not quadriceps muscle biopsies express high levels of utrophin, we investigated by confocal microscopy the expression and distribution of dystrophin and utrophin in the different kinds of myotubes. Quadriceps-derived myotubes (Fig. 5, A-D) showed punctate distribution of dystrophin, with some patches close to the plasma membrane (Fig. $5 \mathrm{~B}$ ), but were negative for utrophin staining (Fig. 5 C). Orbicularis oculi-derived myotubes (Fig. 5, E-H) also showed a punctate distribution of dystrophin (Fig. $5 \mathrm{~F}$ ); these myotubes were also positive for utrophin whose distribution was less homogeneous, had a more filamentous appearance, and was concentrated in areas around the cell periphery (Fig. 5 G). EOM-derived myotubes (Fig. 5, I-L) were similar to orbicularis oculi-derived myotubes in that dystrophin had a punctate distribution (Fig. $5 \mathrm{~J}$ ), whereas utrophin was distributed less homogeneously, had a filamentous appearance, and was concentrated in areas around the cell periphery (Fig. $5 \mathrm{~K}$ ). Interestingly, utrophin and dystrophin appeared to have a separate 

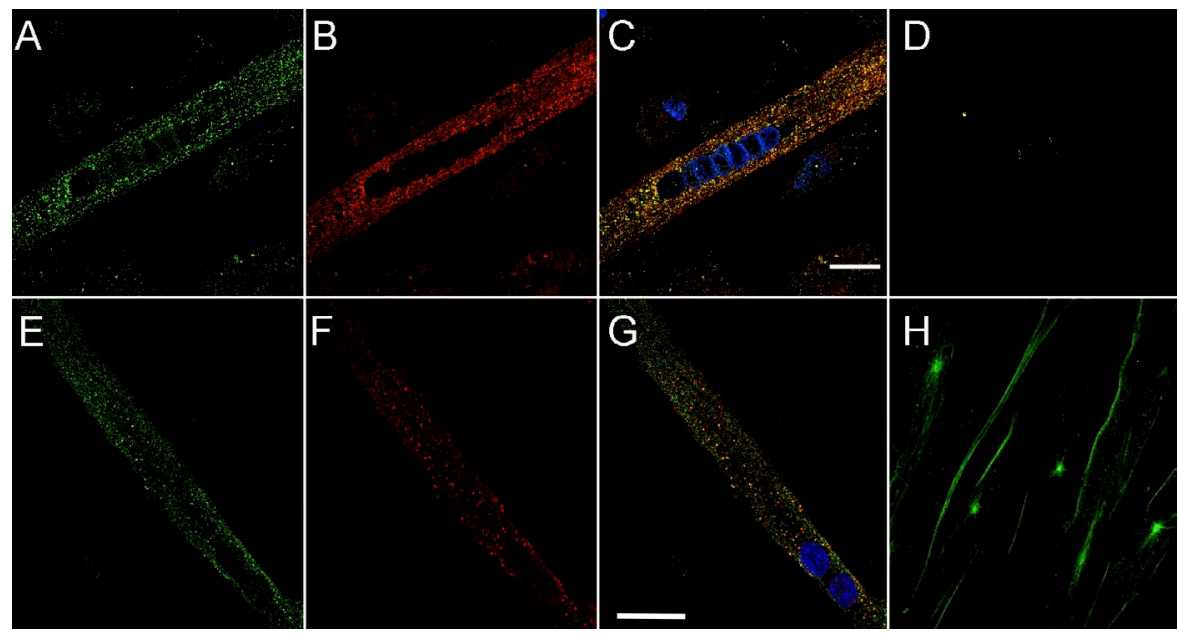

Figure 4. Cellular distribution of RyR1 and $\mathrm{Ca}_{\mathrm{v}} 1.1$ in differentiated orbicularis oculi-derived myotubes. Human myotubes were visualized with an $A 1 R$ confocal microscope equipped with a CFI Apo TIRF 100x objective (1.49 NA) and stained as described in Materials and methods. Top panels show orbicularis oculi, and bottom panels show EOMs. ( $A$ and E) Anti-Cav1.1 (green). (B and F) Anti-RyR1 (red). ( $C$ and $G$ ) Merged image of anti-RyR1, anti-Cav1.1, and DAPI (blue); orange pixels show codistribution of RyR1 and $\mathrm{Ca}_{\mathrm{v}}$ 1.1. (D and H) Anti-Ca 1.2 (green). Bars, $20 \mu \mathrm{m}$.

subcellular distribution that does not overlap within the myotubes (Fig. 5, $\mathrm{H}$ and $\mathrm{L}$ ).

\section{DISCUSSION}

In the present study, we investigated the biochemical and physiological characteristics of orbicularis oculi muscles, a group of facial muscles that are selectively spared or involved in different neuromuscular disorders. As far as the expression of proteins involved in ECC is concerned, it appears that orbicularis oculi muscles are closer to quadriceps than to EOMs. Indeed, the content of skeletal muscle SR proteins was similar between quadriceps and orbicularis oculi muscles and differed from that of EOMs, as only the latter express proteins characteristic of both cardiac and skeletal muscle ECC (Sekulic-Jablanovic et al., 2015). Surprisingly, however, the expression of transcripts did not always match the actual protein content, highlighting the importance of validating arrays or qPCR experiments whenever possible. This was particularly relevant for the difference between the expression of $\mathrm{Ca}_{\mathrm{v}} 1.2$ and dystrophin whose transcripts were increased $>8-10$-fold in orbicularis oculi, but at the protein level they were barely detectable. An intriguing result of this study is that although gene expression in orbicularis oculi is quite different from that in quadriceps, the expression of proteins involved in the ECC process $\left(\mathrm{RyR} 1, \mathrm{Ca}_{\mathrm{v}} 1.1\right.$, SERCA1, CASQ1, and $\mathrm{Ca}_{\mathrm{v}} 1.2$ ) is similar in both cell types. In contrast, in our previous study, the differences in gene expression between EOM and quadriceps were positively correlated with differences in the expression of ECC proteins (Sekulic-Jablanovic et al., 2015). The reason for this discrepancy is at present unclear, but agreement between mRNA and protein content occurs only $\sim 40 \%$ of the time and is influenced by different

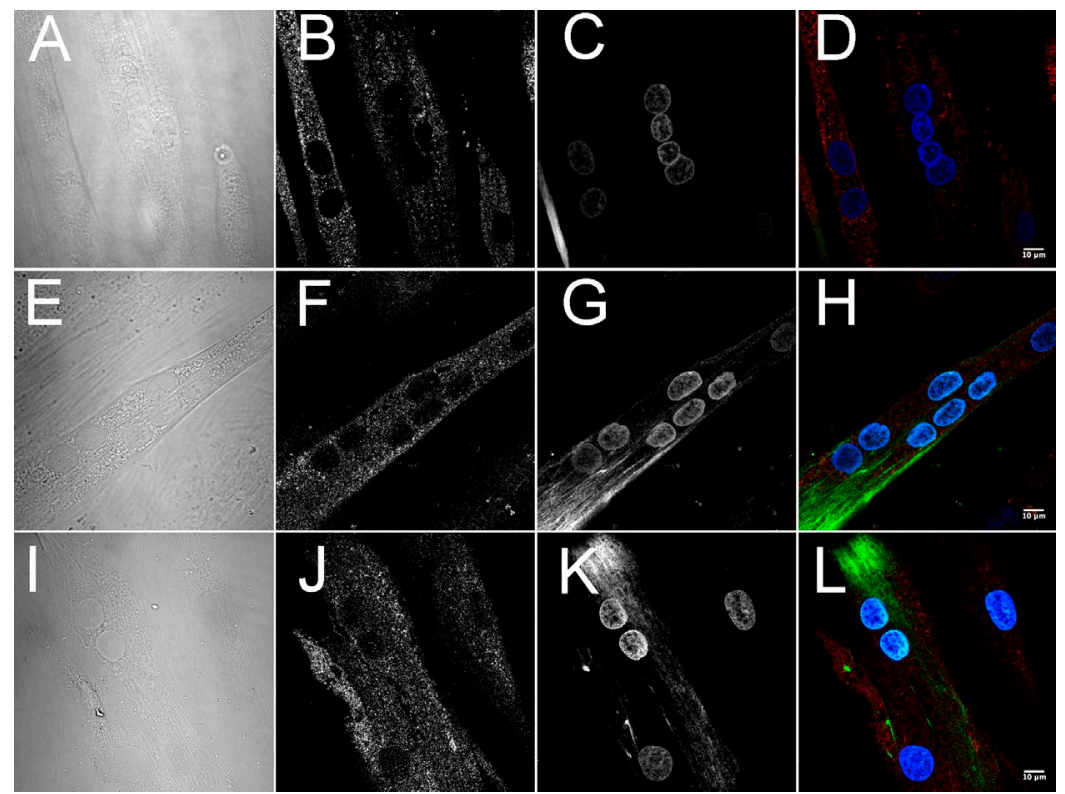

Figure 5. Cellular distribution of dystrophin and utrophin in differentiated myotubes. Human myotubes were visualized with an A1R confocal microscope equipped with a CFI Apo TIRF 100x objective (1.49 NA) and stained as described in Materials and methods. (A-D) Quadriceps-derived myotubes. (E-H) Orbicularis oculi-derived myotubes. (I-L) EOM-derived myotubes. (A, E, and I) Brightfield images. (B, F, and J) Anti-dystrophin. (C, G, and K) Anti-utrophin and DAPI. (D, H, and L) Merged images. Bars, $10 \mu \mathrm{m}$. 
factors, including mRNA and protein stability, the presence of microRNAs, and posttranscriptional modifications, with the key role in determining protein abundance being played at the level of translation (Tian et al., 2004; Vogel et al., 2010; Schwanhäusser et al., 2011). A limited overlap in genomic and proteomic data were reported by Khanna et al. (2003) in EOM and leg muscles and by Zhou et al. (2010) in mouse EOM myosin heavy chain isoform expression.

From a point of view of calcium homeostasis, it appears that orbicularis oculi muscle-derived myotubes are closer to those derived from quadriceps than EOM because the $\mathrm{Ca}^{2+}$ release dose-response curves, the voltage dependence of $\mathrm{Ca}^{2+}$ release, the resting $\left[\mathrm{Ca}^{2+}\right]$, and ionomycin/thapsigargin-sensitive intracellular stores from the two muscle types were functionally indistinguishable and were clearly different from EOM-derived myotubes. The latter have a significantly higher $\mathrm{EC}_{50}$ for 4-cmc-induced $\mathrm{Ca}^{2+}$ release, larger ionomycin/thapsigargin-sensitive intracellular stores, express $\mathrm{Ca}_{\mathrm{v}} 1.2$, and exhibit a threefold larger depolarization-induced $\mathrm{Ca}^{2+}$ influx. The difference in sensitivity to 4-cmc-induced $\mathrm{Ca}^{2+}$ release but not $\mathrm{KCl}$-induced $\mathrm{Ca}^{2+}$ release may reflect the different amounts of RyR1 and RyR3 expressed in EOM-derived myotubes. Such a hypothesis is compatible with previous findings (Fessenden et al., 2000; Matyash et al., 2002; Sekulic-Jablanovic et al., 2015) who showed that (a) EOM biopsies contain 100-times more RYR3 transcript than triceps biopsies, whereas orbicularis oculi express only $\sim 4$-times more; (b) RyR3 have a significantly lower sensitivity to 4-cmc; and (c) in reconstituted 1B5 myotubes, RyR3 cannot form functional contacts with the DHPR and therefore would not contribute directly to the KCl-induced $\mathrm{Ca}^{2+}$ release.

One of the physiological characteristics of EOMs is that they are fatigue resistant (Fuchs and Binder, 1983), and this may be functionally related to the high levels of expression of $\mathrm{Ca}_{\mathrm{v}} 1.2$ and consequent large $\mathrm{Ca}^{2+}$ influx. The $\mathrm{Ca}^{2+}$ influx may be used as a means (a) to activate ECC more rapidly by enhancing $\mathrm{Ca}^{2+}$ induced $\mathrm{Ca}^{2+}$ release or (b) to rapidly replenish intracellular stores. Depolarization-induced $\mathrm{Ca}^{2+}$ influx is less pronounced in myotubes derived from other skeletal muscles, most likely because they lack the cardiac isoform of the $\alpha 1$ DHPR subunit.

Although orbicularis oculi express a typical skeletal muscle ECC, they also show similarities with EOMs in that they express MyHC13 and high levels of RYR3. In humans, orbicularis oculi are composed of $90 \%$ type II fibers and 10\% type I fibers (Wirtschafter et al., 1994; Campbell et al., 1999), but our results show that they also express MyH13. In a study on levator palpebrae and retractor bulbi muscles from different species, it was shown that the latter muscles also express MyHC13 and that this is probably responsible for their rapid contracture times $(<10 \mathrm{~ms})$; in fact, limb muscles do not express the superfast myosin isoforms, and their contracture time is approximately five times longer (Lucas and Hoh, 1997). As far as RYR3 expression is concerned, our results are enigmatic because, in general, RYR3 transcripts are expressed at low levels, if at all, in adult skeletal muscle (Martin et al., 1998), and the role of RyR3 is unclear. RYR3KO mice are viable, and their muscles show no obvious physiological differences compared with their wild-type littermates, including no changes in electrically induced $\mathrm{Ca}^{2+}$ release and contractile properties of adult muscle fibers, although skeletal muscles from neonatal RYR3 KO mice show decreased tension development (Takeshima et al., 1996). Although for the time being the function of RyR3s is speculative, it is possible that these channels act as amplifiers of the $\mathrm{Ca}^{2+}$ signals; compatibly, RYR3KO mice were reported to have a mild cognitive impairment when tested on a water maize (Balschun et al., 1999), but retrospectively, this may have also been related to a visual impairment. Studies aimed at understanding the role of RyR3 in EOMs are currently under way.

Our results concerning the expression of utrophin are interesting and most likely explain why in patients with Duchenne muscular dystrophy ocular and facial muscles are spared. Furthermore, the observation that EOMs are spared in Duchenne muscular dystrophy even though they exhibit a large $\mathrm{Ca}^{2+}$ influx provides strong evidence that controlled $\mathrm{Ca}^{2+}$ influx, per se, is not deleterious to skeletal muscles as recently proposed (Millay et al., 2009), but is actually a physiological mechanism used by some skeletal muscles. Utrophin and dystrophin share considerable sequence and structural similarity (Tinsley et al., 1992; Winder et al., 1995), and utrophin can associate with the dystrophin-associated complex, serving as a link between actin and the extracellular matrix (Matsumura et al., 1992). Interestingly, in cultured myotubes, the subcellular distribution of utrophin differs from that of dystrophin. Indeed, and as previously reported (Trimarchi et al., 2006) and confirmed in the present study, after 7-10 d of differentiation, dystrophin has a punctate membrane distribution, whereas utrophin has a patchy more filamentous distribution concentrated within specific subcellular domains. The reason for this difference is unclear but may reflect distinct binding partners of the two proteins. In mdx mice, it is believed that utrophin compensates for the lack of dystrophin (Wakefield et al., 2000). Based on our results and on the fact that mdx knocked out also for utrophin show EOM involvement (Baker et al., 2006), it appears that utrophin can functionally compensate in vivo for the lack of dystrophin, supporting the current strategies aimed at modulating utrophin expression in the therapy for Duchenne muscular dystrophy (Perkins and Davies, 2002; Chakkalakal et al., 2005; Guiraud et al., 2015). 
Collectively, these studies show that subspecialization of skeletal muscles occurs through multiple factors; although it is true that muscle innervation plays a prominent role, the distribution of a specific muscle within a niche devoted to a precise physiological function is also important. Indeed, the term muscle allotype was proposed to describe the different capacities of myogenic cells of different lineages to express a different subset of myofibrillar genes. Because EOMs, orbicularis oculi, and levator palpebrae (and the retractor bulbi which is present in some mammals but not in humans) are derived from cells from a different lineage than those giving rise to limb muscles, their myogenic precursors must be programmed to express different subsets of proteins. The present study substantiates the validity of the muscle allotype hypothesis because we show that satellite cells derived from different muscles are primed and will follow the developmental characteristics of their muscle of origin, a property that can be exploited in laboratories devoted to tissue engineering.

\section{ACKNOWLEDGMENTS}

We gratefully acknowledge the technical support of AnneSylvie Monnet.

This work was supported by the Swiss National Science Foundation (SNF; grant number 31003A-146198) and by the Department of Anesthesia Basel University Hospital.

The authors declare no competing financial interests.

Eduardo Ríos served as editor.

Submitted: 9 November 2015

Accepted: 25 March 2016

\section{REFERENCES}

Anderson, A.A., S. Treves, D. Biral, R. Betto, D. Sandonà, M. Ronjat, and F. Zorzato. 2003. The novel skeletal muscle sarcoplasmic reticulum JP-45 protein. Molecular cloning, tissue distribution, developmental expression, and interaction with $\alpha 1.1$ subunit of the voltage-gated calcium channel. J. Biol. Chem. 278:3998739992. http://dx.doi.org/10.1074/jbc.M305016200

Baker, P.E., J.A. Kearney, B. Gong, A.P. Merriam, D.E. Kuhn, J.D. Porter, and J.A. Rafael-Fortney. 2006. Analysis of gene expression differences between utrophin/dystrophin-deficient vs $\mathrm{mdx}$ skeletal muscles reveals a specific upregulation of slow muscle genes in limb muscles. Neurogenetics. 7:81-91. http://dx.doi.org /10.1007/s10048-006-0031-7

Balschun, D., D.P. Wolfer, F. Bertocchini, V. Barone, A. Conti, W. Zuschratter, L. Missiaen, H.P. Lipp, J.U. Frey, and V. Sorrentino. 1999. Deletion of the ryanodine receptor type 3 (RyR3) impairs forms of synaptic plasticity and spatial learning. EMBOJ. 18:52645273. http://dx.doi.org/10.1093/emboj/18.19.5264

Bannister, R.A., I.N. Pessah, and K.G. Beam. 2009. The skeletal L-type $\mathrm{Ca}^{2+}$ current is a major contributor to excitation-coupled $\mathrm{Ca}^{2+}$ entry. J. Gen. Physiol. 133:79-91. http://dx.doi.org/10.1085 /jgp.200810105

Bers, D.M. 2002. Cardiac excitation-contraction coupling. Nature. 415:198-205. http://dx.doi.org/10.1038/415198a

Campbell, S.P., D.A. Williams, B.R. Frueh, and G.S. Lynch. 1999. Contractile activation characteristics of single permeabilized fibres from levator palpebrae superioris, orbicularis oculi and vastus lateralis muscles from humans. J. Physiol. 519:615-622. http://dx.doi.org/10.1111/j.1469-7793.1999.0615m.x

Caputo, C. 2011. Pharmacological investigations of excitation-contraction coupling. Compr. Physiol. 1:381-415.

Censier, K., A. Urwyler, F. Zorzato, and S. Treves. 1998. Intracellular calcium homeostasis in human primary muscle cells from malignant hyperthermia-susceptible and normal individuals. Effect Of overexpression of recombinant wild-type and Arg163Cys mutated ryanodine receptors. J. Clin. Invest. 101:1233-1242. http://dx.doi.org/10.1172/JCI993

Chakkalakal, J.V., J. Thompson, R.J. Parks, and B.J. Jasmin. 2005. Molecular, cellular, and pharmacological therapies for Duchenne/Becker muscular dystrophies. FASEB J. 19:880-891. http://dx.doi.org/10.1096/fj.04-1956rev

Clarke, N.F., L.B. Waddell, S.T. Cooper, M. Perry, R.L. Smith, A.J. Kornberg, F. Muntoni, S. Lillis, V. Straub, K. Bushby, et al. 2010. Recessive mutations in RYR1 are a common cause of congenital fiber type disproportion. Hum. Mutat. 31:E1544-E1550. http:// dx.doi.org/10.1002/humu.21278

Ducreux, S., F. Zorzato, C. Müller, C. Sewry, F. Muntoni, R. Quinlivan, G. Restagno, T. Girard, and S. Treves. 2004. Effect of ryanodine receptor mutations on interleukin- 6 release and intracellular calcium homeostasis in human myotubes from malignant hyperthermia-susceptible individuals and patients affected by central core disease. J. Biol. Chem. 279:43838-43846. http://dx.doi.org/10.1074/jbc.M403612200

Fessenden, J.D., Y. Wang, R.A. Moore, S.R.W. Chen, P.D. Allen, and I.N. Pessah. 2000. Divergent functional properties of ryanodine receptor types 1 and 3 expressed in a myogenic cell line. Biophys. J. 79:2509-2525. http://dx.doi.org/10.1016/S0006 $-3495(00) 76492-7$

Fuchs, A.F., and M.D. Binder. 1983. Fatigue resistance of human extraocular muscles. J. Neurophysiol. 49:28-34.

Gray, H., and W.H. Lewis. 1918. Anatomy of the Human Body. Twentieth edition. Lea \& Febiger, Philadelphia. http://dx.doi .org/10.5962/bhl.title.20311

Guiraud, S., S.E. Squire, B. Edwards, H. Chen, D.T. Burns, N. Shah, A. Babbs, S.G. Davies, G.M. Wynne, A.J. Russell, et al. 2015. Second-generation compound for the modulation of utrophin in the therapy of DMD. Hum. Mol. Genet. 24:4212-4224. http://dx .doi.org/10.1093/hmg/ddv154

Jungbluth, H., H. Zhou, L. Hartley, B. Halliger-Keller, S. Messina, C. Longman, M. Brockington, S.A. Robb, V. Straub, T. Voit, et al. 2005. Minicore myopathy with ophthalmoplegia caused by mutations in the ryanodine receptor type 1 gene. Neurology. 65:1930-1935. http ://dx.doi.org/10.1212/01.wnl.0000188870.37076.f2

Kallestad, K.M., S.L. Hebert, A.A. McDonald, M.L. Daniel, S.R. Cu, and L.K. McLoon. 2011. Sparing of extraocular muscle in aging and muscular dystrophies: a myogenic precursor cell hypothesis. Exp. Cell Res. 317:873-885. http://dx.doi.org/10.1016/j.yexcr .2011 .01 .018

Kaminski, H.J., M. al-Hakim, R.J. Leigh, M.B. Katirji, and R.L. Ruff. 1992. Extraocular muscles are spared in advanced Duchenne dystrophy. Ann. Neurol. 32:586-588. http://dx.doi.org/10.1002/ ana.410320418

Khanna, S., A.P. Merriam, B. Gong, P. Leahy, and J.D. Porter. 2003. Comprehensive expression profiling by muscle tissue class and identification of the molecular niche of extraocular muscle. FASEB J. 17:1370-1372.

Khurana, T.S., R.A. Prendergast, H.S. Alameddine, F.M. Tomé, M. Fardeau, K. Arahata, H. Sugita, and L.M. Kunkel. 1995. Absence of extraocular muscle pathology in Duchenne's muscular dystrophy: role for calcium homeostasis in extraocular muscle 
sparing. J. Exp. Med. 182:467-475. http://dx.doi.org/10.1084/ jem.182.2.467

Lopez, R.J., B. Mosca, S. Treves, M. Maj, L. Bergamelli, J.C. Calderon, C.F. Bentzinger, K. Romanino, M.N. Hall, M.A. Rüegg, et al. 2015. Raptor ablation in skeletal muscle decreases Cav1.1 expression and affects the function of the excitation-contraction coupling supramolecular complex. Biochem. J. 466:123-135. http ://dx.doi.org/10.1042/BJ20140935

Lucas, C.A., and J.F. Hoh. 1997. Extraocular fast myosin heavy chain expression in the levator palpebrae and retractor bulbi muscles. Invest. Ophthalmol. Vis. Sci. 38:2817-2825.

Martin, C., K.E. Chapman, J.R. Seckl, and R.H. Ashley. 1998. Partial cloning and differential expression of ryanodine receptor/ calcium-release channel genes in human tissues including the hippocampus and cerebellum. Neuroscience. 85:205-216. http:// dx.doi.org/10.1016/S0306-4522(97)00612-X

Matsumura, K., J.M. Ervasti, K. Ohlendieck, S.D. Kahl, and K.P. Campbell. 1992. Association of dystrophin-related protein with dystrophin-associated proteins in $\mathrm{mdx}$ mouse muscle. Nature. 360:588-591. http://dx.doi.org/10.1038/360588a0

Matyash, M., V. Matyash, C. Nolte, V. Sorrentino, and H. Kettenmann. 2002. Requirement of functional ryanodine receptor type 3 for astrocyte migration. FASEB J. 16:84-86.

Millay, D.P., S.A. Goonasekera, M.A. Sargent, M. Maillet, B.J. Aronow, and J.D. Molkentin. 2009. Calcium influx is sufficient to induce muscular dystrophy through a TRPC-dependent mechanism. Proc. Natl. Acad. Sci. USA. 106:19023-19028. http:// dx.doi.org/10.1073/pnas.0906591106

Miller, N.R., N.J. Newman, V. Biousse, and J.B. Kerrison, editors. 2008. Walsh and Hoyt's Clinical Neuro-Ophthalmology: The Essentials. Second edition. Lippincott Williams \& Wilkins, Philadelphia. 592 pp.

Moore, K.L., T.V.N. Persaud, and M.G. Torchia. 2015. The Developing Human: Clinically Oriented Embryology. Tenth edition. Elsevier, Philadelphia. 560 pp.

Ouattara, D., C. Vacher, J.J.A. de Vasconcellos, S. Kassanyou, G. Gnanazan, and B. N'Guessan. 2004. Anatomical study of the variations in innervation of the orbicularis oculi by the facial nerve. Surg. Radiol. Anat. 26:51-53. http://dx.doi.org/10.1007/ s00276-003-0168-0

Perkins, K.J., and K.E. Davies. 2002. The role of utrophin in the potential therapy of Duchenne muscular dystrophy. Neuromuscul. Disord. 12:S78-S89. http://dx.doi.org/10.1016/S0960 -8966(02) 00087-1

Porter, J.D., J.A. Rafael, R.J. Ragusa, J.K. Brueckner, J.I. Trickett, and K.E. Davies. 1998. The sparing of extraocular muscle in dystrophinopathy is lost in mice lacking utrophin and dystrophin. J. Cell Sci. 111:1801-1811.

Ríos, E., and G. Pizarro. 1991. Voltage sensor of excitation-contraction coupling in skeletal muscle. Physiol. Rev. 71:849-908.

Rokach, O., N.D. Ullrich, M. Rausch, V. Mouly, H. Zhou, F. Muntoni, F. Zorzato, and S. Treves. 2013. Establishment of a human skeletal muscle-derived cell line: biochemical, cellular and electrophysiological characterization. Biochem. J. 455:169177. http://dx.doi.org/10.1042/BJ20130698

Sadeh, M., and L.Z. Stern. 1984. Observations on the innervation of human extraocular muscles. J. Neurol. Sci. 66:295-305. http://dx .doi.org/10.1016/0022-510X(84)90018-2

Schiaffino, S., and C. Reggiani. 2011. Fiber types in mammalian skeletal muscles. Physiol. Rev. 91:1447-1531. http://dx.doi.org /10.1152/physrev.00031.2010

Schwanhäusser, B., D. Busse, N. Li, G. Dittmar, J. Schuchhardt, J. Wolf, W. Chen, and M. Selbach. 2011. Global quantification of mammalian gene expression control. Nature. 473:337-342. http://dx.doi.org/10.1038/nature10098
Sekulic-Jablanovic, M., A. Palmowski-Wolfe, F. Zorzato, and S. Treves. 2015. Characterization of excitation-contraction coupling components in human extraocular muscles. Biochem. J. 466:2936. http://dx.doi.org/10.1042/BJ20140970

Spencer, R.F., and J.D. Porter. 1988. Structural organization of the extraocular muscles. Rev. Oculomot. Res. 2:33-79.

Takeshima, H., T. Ikemoto, M. Nishi, N. Nishiyama, M. Shimuta, Y. Sugitani, J. Kuno, I. Saito, H. Saito, M. Endo, et al. 1996. Generation and characterization of mutant mice lacking ryanodine receptor type 3. J. Biol. Chem. 271:19649-19652. http://dx.doi.org/10.1074/jbc.271.33.19649

Talmadge, R.J., and R.R. Roy. 1993. Electrophoretic separation of rat skeletal muscle myosin heavy-chain isoforms. J. Appl. Physiol. 75:2337-2340.

Taylor, A., K. Lachlan, R.M. Manners, and A.J. Lotery. 2012. A study of a family with the skeletal muscle RYR1 mutation (c.7354C $>\mathrm{T}$ ) associated with central core myopathy and malignant hyperthermia susceptibility. J. Clin. Neurosci. 19:65-70. http://dx .doi.org/10.1016/j.jocn.2011.05.010

Tian, Q., S.B. Stepaniants, M. Mao, L. Weng, M.C. Feetham, M.J. Doyle, E.C. Yi, H. Dai, V. Thorsson, J. Eng, et al. 2004. Integrated genomic and proteomic analyses of gene expression in Mammalian cells. Mol. Cell. Proteomics. 3:960-969. http://dx .doi.org/10.1074/mcp.M400055-MCP200

Tinsley, J.M., D.J. Blake, A. Roche, U. Fairbrother, J. Riss, B.C. Byth, A.E. Knight, J. Kendrick-Jones, G.K. Suthers, D.R. Love, et al. 1992. Primary structure of dystrophin-related protein. Nature. 360:591-593. http://dx.doi.org/10.1038/360591a0

Treves, S., H. Jungbluth, F. Muntoni, and F. Zorzato. 2008. Congenital muscle disorders with cores: the ryanodine receptor calcium channel paradigm. Curr. Opin. Pharmacol. 8:319-326. http ://dx.doi.org/10.1016/j.coph.2008.01.005

Treves, S., M. Vukcevic, P.Y. Jeannet, S. Levano, T. Girard, A. Urwyler, D. Fischer, T. Voit, H. Jungbluth, S. Lillis, et al. 2011. Enhanced excitation-coupled $\mathrm{Ca}^{2+}$ entry induces nuclear translocation of NFAT and contributes to IL-6 release from myotubes from patients with central core disease. Hum. Mol. Genet. 20:589-600. http://dx.doi.org/10.1093/hmg/ddq506

Trimarchi, F., A. Favaloro, S. Fulle, L. Magaudda, C. Puglielli, and D. Di Mauro. 2006. Culture of human skeletal muscle myoblasts: timing appearance and localization of dystrophin-glycoprotein complex and vinculin-talin-integrin complex. Cells Tissues Organs (Print). 183:87-98. http://dx.doi.org/10.1159/000095513

Ullrich, N.D., D. Fischer, C. Kornblum, M.C. Walter, E. Niggli, F. Zorzato, and S. Treves. 2011. Alterations of excitation-contraction coupling and excitation coupled $\mathrm{Ca}^{2+}$ entry in human myotubes carrying CAV3 mutations linked to rippling muscle disease. Hum. Mutat. 32:309-317. http://dx.doi.org/10.1002/humu.21431

Vogel, C., R.S. Abreu, D. Ko, S.Y. Le, B.A. Shapiro, S.C. Burns, D. Sandhu, D.R. Boutz, E.M. Marcotte, and L.O. Penalva. 2010. Sequence signatures and mRNA concentration can explain twothirds of protein abundance variation in a human cell line. Mol. Syst. Biol. 6:400. http://dx.doi.org/10.1038/msb.2010.59

Vukcevic, M., F. Zorzato, S. Keck, D.A. Tsakiris, J. Keiser, R.M. Maizels, and S. Treves. 2013. Gain of function in the immune system caused by a ryanodine receptor 1 mutation. J. Cell Sci. 126:3485-3492. http://dx.doi.org/10.1242/jcs.130310

Wakefield, P.M., J.M. Tinsley, M.J. Wood, R. Gilbert, G. Karpati, and K.E. Davies. 2000. Prevention of the dystrophic phenotype in dystrophin/utrophin-deficient muscle following adenovirusmediated transfer of a utrophin minigene. Gene Ther. 7:201-204. http://dx.doi.org/10.1038/sj.gt.3301066

Wieczorek, D.F., M. Periasamy, G.S. Butler-Browne, R.G. Whalen, and B. Nadal-Ginard. 1985. Co-expression of multiple myosin 
heavy chain genes, in addition to a tissue-specific one, in extraocular musculature. J. Cell Biol. 101:618-629. http://dx.doi .org/10.1083/jcb.101.2.618

Wilmshurst, J.M., S. Lillis, H. Zhou, K. Pillay, H. Henderson, W. Kress, C.R. Müller, A. Ndondo, V. Cloke, T. Cullup, et al. 2010. RYR1 mutations are a common cause of congenital myopathies with central nuclei. Ann. Neurol. 68:717-726. http://dx.doi.org /10.1002/ana.22119

Winder, S.J., T.J. Gibson, and J. Kendrick-Jones. 1995. Dystrophin and utrophin: the missing links! FEBS Lett. 369:27-33. http://dx .doi.org/10.1016/0014-5793(95)00398-S

Wirtschafter, J.D., T. Lander, R.H. Baker, M. Stevanoviç, J. Kirsch, and L.K. McLoon. 1994. Heterogeneous length and in-series ar- rangement of orbicularis oculi muscle: individual myofibers do not extend the length of the eyelid. Trans. Am. Ophthalmol. Soc. 92:71-88.

Wright, K.W., P.H. Spiegel, and L.S. Thompson, editors. 2006. Handbook of Pediatric Neuro-Ophthalmology. Springer-Verlag New York, New York. 464 pp. http://dx.doi.org/10.1007/0-387 $-27930-\mathrm{X}$

Zhou, Y., D. Liu, and H.J. Kaminski. 2010. Myosin heavy chain expression in mouse extraocular muscle: more complex than expected. Invest. Ophthalmol. Vis. Sci. 51:6355-6363. http://dx .doi.org/10.1167/iovs.10-5937 